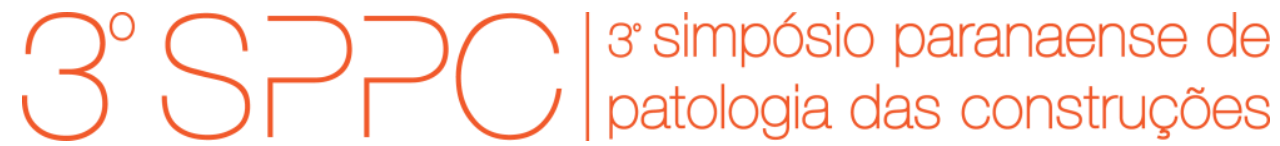

ISSN 2526-7248 artigo n. 3SPPC1003, pp. 25-34, 2018

\title{
Avaliação do efeito mitigador do pó de concreto proveniente de RCD no ataque por sulfatos de sódio em barras de argamassa
}

\author{
Brekailo, Fernanda ${ }^{1}$; Pereira, Elias ${ }^{2}$; Pereira, Eduardo ${ }^{3}$ \\ ${ }^{1}$ Mestranda, Universidade Estadual de Ponta Grossa, nandabrekailo@hotmail.com \\ ${ }^{2}$ Mestre, Universidade Estadual de Ponta Grossa, elias_pereira@outlook.com \\ ${ }^{3}$ Doutor, Universidade Estadual de Ponta Grossa, eduardopereira@uepg.br
}

Resumo: O concreto pode estar sujeito a diversos fenômenos de degradação, entre eles o ataque por sulfatos. A incorporação de adições minerais em substituição parcial ao cimento provoca alterações na microestrutura do material, podendo mitigar a degradação ocasionada neste tipo de ataque. No presente trabalho realizou-se o estudo do reaproveitamento de pó de concreto de resíduo de construção e demolição (RCD) como adição mineral em barras de argamassa, afim de avaliar seu efeito mitigador do ataque por sulfatos de sódio, conforme a NBR 13583. Os resultados indicam que a adição não possui capacidade de mitigar o ataque externo por sulfatos de sódio, pois na determinação da variação dimensional das barras, as diferentes porcentagens de substituição do pó de concreto na composição do material ligante apresentaram expansões maiores que a argamassa de referência. Tanto a argamassa de referência como a contendo $20 \%$ de resíduo de concreto apresentaram grande quantidade de cristais de etringita em sua microestrutura após o ataque, acompanhada de uma redução na sua porosidade.

Palavras-chave: Pó de concreto, RCD, Argamassa, Ataque por sulfatos.

Abstract: Concrete may be subject to several phenomena of degradation, among them the attack by sulfates. Incorporation of mineral additions in partial replacement to the cement causes changes in the microstructure of the material, and can mitigate the degradation caused in this type of attack. In the present article were performed studies on the reutilization of concrete from construction and demolition waste (CDW) as a mineral addition in mortar bars, in order to evaluate its mitigating effect of attack by sodium sulphates, according to NBR 13583. The results indicate that the addition does not have the capacity to mitigate the external attack by sodium sulphates, because in the determination of the dimensional variation of the bars, the different percentages of substitution of the concrete powder in the composition of the binder material presented larger expansions than those at the reference mortar. Both the reference mortar and the one containing $20 \%$ of concrete residue presented a large amount of crystallites of ettringite in its microstructure after the attack, accompanied by a reduction in its porosity.

Keywords: Concrete powder; CDW; Mortar; Sulphate attack. 


\section{Introdução}

O concreto, devido ao seu baixo custo relativo e versatilidade, é o material mais utilizado na construção civil. Sendo assim, é fundamental que este material seja capaz de resistir aos processos de deterioração devido aos agentes agressivos do meio, mantendo a capacidade de desempenhar sua função prevista, preservando suas propriedades, resistências mecânicas e condição de utilização [1-3].

Os processos de deterioração podem ter origem em fenômenos físicos, químicos ou mecânicos, mas raramente possuem uma única causa, podendo ocorrer por diversos fatores simultaneamente [2-3]. Entre os processos de deterioração com origem em fenômenos químicos encontra-se o ataque por sulfatos. Os íons $\mathrm{SO}_{4}{ }^{2-}$, que podem ter origem interna e externa, presentes na solução de poros da matriz cimentícia, reagem com os compostos da hidratação do cimento, como o hidróxido de cálcio (portlandita), silicato de cálcio hidratado (C-S-H) e o monossulfato de cálcio hidratado (AFm). Esta reação tem produtos com volume maior do que os que Ihe deram origem, como a gipsita, a etringita, e em casos específicos, a taumasita. Este aumento no volume pode causar expansão com consequente fissuração do concreto, e ainda levar a uma diminuição progressiva na sua resistência e perda de massa $[2,4]$.

A agressividade do ataque está relacionada ao tipo de cátion associado ao sulfato. Destaca-se entre eles o sulfato de sódio $\left(\mathrm{Na}_{2} \mathrm{SO}_{4}\right)$, por ser o mais comum de ser encontrado na natureza, presente em ambientes marinho e de respingos de maré, além de efluentes industriais [5-6]. O sulfato de sódio pode interagir com dois produtos da hidratação do cimento, o hidróxido de cálcio e o monossulfato hidratado, conforme mostra a Equação 1 e a Equação 2, respectivamente.

$$
\begin{aligned}
& \mathrm{Na}_{2} \mathrm{SO}_{4}+\mathrm{Ca}(\mathrm{OH})_{2}+2 \mathrm{H}_{2} \mathrm{O} \rightarrow \mathrm{CaSO}_{4} \cdot 2 \mathrm{H}_{2} \mathrm{O}+2 \mathrm{NaOH} \\
& \text { Hidróxido de cálcio Gipsita Hidróxido de sódio } \\
& 2\left(\mathrm{CaSO}_{4} \cdot 2 \mathrm{H}_{2} \mathrm{O}\right)+4 \mathrm{CaO} \cdot \mathrm{Al}_{2} \mathrm{O}_{3} \cdot \mathrm{SO}_{3} \cdot 12 \mathrm{H}_{2} \mathrm{O} \rightarrow 6 \mathrm{CaO} \cdot \mathrm{Al}_{2} \mathrm{O}_{3} \cdot 3 \mathrm{SO}_{3} \cdot 32 \mathrm{H}_{2} \mathrm{O} \\
& \text { Gipsita Monossulfado hidratado Etringita }
\end{aligned}
$$

Uma forma de mitigar o ataque por sulfatos de origem externa é dificultar o fluxo de fluídos que possam transportar íons sulfatos para o interior da estrutura utilizando um concreto de baixa permeabilidade, sendo possível obter este material utilizando adições minerais junto ao cimento Portland, que tendem a alterar a estrutura porosa do concreto promovendo um tamponamento dos poros do material [7-8].

O uso de adições minerais provoca alterações no concreto que definem o seu desempenho. Essas alterações ocorrem devido ao efeito fíler pela presença de pequenas partículas que tamponam os poros, somado ao efeito das reações pozolânicas no caso de adições reativas [8-9]. Além disso, sua incorporação na composição do material ligante traz benefícios econômicos e ambientais, visto que as adições são em grande parte resíduos de outros processos. Desta forma, é possível reutilizar passivos ambientais, e ainda preservar recursos naturais e reduzir o consumo de energia envolvido na produção de cimento Portland [10].

No intuito de encontrar novos materiais que possam ser utilizados como adições minerais, destaca-se as pesquisas sobre o resíduo de concreto. Estudos indicam 
que este material pode ser utilizado como adição de caráter inerte, com comportamento similar ao do fíler calcário, agindo como material de enchimento e ponto de nucleação para a hidratação do cimento [11-13]. O presente trabalho teve como objetivo realizar o estudo de uma alternativa de aproveitamento do pó de concreto, oriundo de resíduo de construção e demolição, avaliando sua capacidade de mitigação do ataque por sulfatos de sódio de origem externa.

\section{Materiais e Métodos}

O resíduo de concreto utilizado é proveniente de resíduos de construção e demolição - RCD. Primeiramente, o material passou por um pré-beneficiamento em equipamento de abrasão Los Angeles, tendo o resultante sido peneirado para obtenção do material passante na peneira 200 (abertura de 0,075 mm). A caracterização química do resíduo de concreto está apresentada na Tabela 1. No difratograma de raios $X$ deste material (Figura 1) são identificados picos predominantes de quartzo $\left(\mathrm{SiO}_{2}\right)$, calcita $\left(\mathrm{CaCO}_{3}\right)$, portlandita $\left(\mathrm{Ca}(\mathrm{OH})_{2}\right)$ e periclásio $(\mathrm{MgO})$. O resíduo de concreto não apresentou halo amorfo, indicando que constitui uma adição de caráter inerte.

Tabela 1: Caracterização química do pó de concreto

\begin{tabular}{ccccccccc}
\hline \multicolumn{8}{c}{ Composição Química (\%) } \\
\hline $\mathrm{SiO}_{2}$ & $\mathrm{CaO}$ & $\mathrm{Fe}_{2} \mathrm{O}_{3}$ & $\mathrm{Al}_{2} \mathrm{O}_{3}$ & $\mathrm{~K}_{2} \mathrm{O}$ & $\mathrm{SO}_{3}$ & $\mathrm{TiO}_{2}$ & $\mathrm{MnO}$ & Álcalis totais \\
27,41 & 52,23 & 8,60 & 7,35 & 1,45 & 1,15 & 1,33 & 0,48 & 0,95 \\
\hline
\end{tabular}

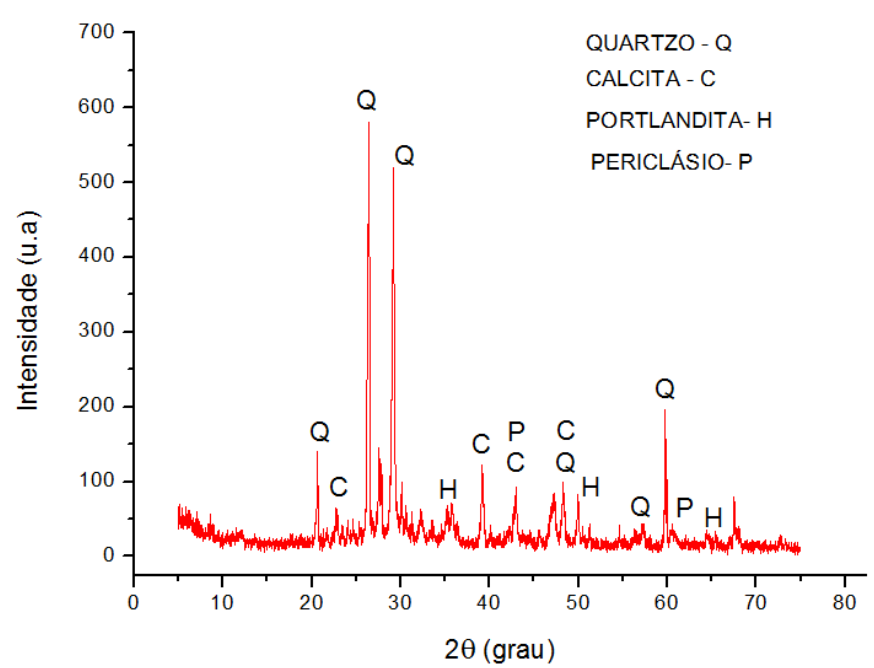

Figura 1: Difratograma de raios- $\mathrm{X}$ da amostra de pó de concreto.

O material foi então utilizado como substituição parcial ao cimento em argamassas e avaliadas quanto ao potencial de mitigação ao ataque por sulfatos em solução de sulfato de sódio, conforme NBR 13583 [14]. Utilizaram-se 5 traços, cada um com diferentes porcentagens de substituição: referência (sem adição), 3\%, 5\%, 12\% e $20 \%$. Na Tabela 2 está apresentado as proporções de mistura das argamassas em massa.

Para preparação das argamassas, a distribuição granulometrica do agregado miúdo foi composta por 4 frações iguais da série normal, sendo elas as frações retidas nas peneiras de abertura da malha de 1,20, 0,60, 0,30 e 0,15 mm, conforme recomendações da NBR 7214 [15]. O cimento Portland utilizado foi do tipo CPIIF-40. 
BREKAILO, F.; PEREIRA, E.; PEREIRA, E., AVALIAÇÃO DO EFEITO MITIGADOR DO PÓ DE CONCRETO PROVENIENTE DE RCD NO ATAQUE POR SULFATOS DE SÓDIO EM BARRAS DE ARGAMASSA. $3^{\circ}$ Simpósio Paranaense de Patologia das Construções (30 SPPC), artigo 3SPPC1003, pp. 25 - 34, 2018. DOI: 10.4322/2526-7248.003

Os resultados da caracterização físico-química do cimento Portland constam na Tabela 3 e todos os índices apresentam valores dentro dos limites da especificação.

Tabela 2: Proporção de mistura das argamassas para avaliação do potencial de mitigação ao ataque por sulfatos em solução de sulfato de sódio

\begin{tabular}{|c|c|c|c|c|}
\hline \multirow[b]{2}{*}{ Argamassas } & \multicolumn{4}{|c|}{ Massa dos materiais (g) } \\
\hline & Cimento & $\begin{array}{c}\text { Areia } \\
\text { normal }\end{array}$ & $\begin{array}{c}\text { Resíduo de } \\
\text { Concreto }\end{array}$ & Água \\
\hline $0 \%$ de substituição & 750 & \multirow{5}{*}{2400} & - & \multirow{5}{*}{450} \\
\hline 3\% de substituição & 727,5 & & 22,5 & \\
\hline $5 \%$ de substituição & 712,5 & & 37,5 & \\
\hline $12 \%$ de substituição & 660 & & 90 & \\
\hline $20 \%$ de substituição & 600 & & 150 & \\
\hline
\end{tabular}

Tabela 3: Caracterização físico química do cimento CPII-F-40

\begin{tabular}{|c|c|c|c|c|c|c|c|c|c|}
\hline \multicolumn{10}{|c|}{ Ensaios Químicos (\%) } \\
\hline \multirow{2}{*}{$\begin{array}{c}\text { Perda } \\
\text { ao fogo } \\
4,59\end{array}$} & $\mathrm{CaO}$ & $\mathrm{SiO}_{2}$ & $\mathrm{MgO}$ & $\mathrm{A}_{1} 2 \mathrm{O}_{3}$ & $\mathrm{SO}_{3}$ & $\mathrm{Fe}_{2} \mathrm{O}_{3}$ & $\mathrm{~K}_{2} \mathrm{O}$ & $\mathrm{TiO}_{2}$ & \multirow{2}{*}{$\begin{array}{c}\text { Resíduo } \\
\text { insolúvel } \\
0,99\end{array}$} \\
\hline & 74,73 & 11,31 & 3,58 & 3,25 & 3,01 & 2,48 & 1,36 & 0,27 & \\
\hline \multicolumn{10}{|c|}{ Ensaios Físicos } \\
\hline \multirow{3}{*}{\multicolumn{2}{|c|}{$\begin{array}{c}\text { Massa Espec. } \\
\left(\mathrm{g} / \mathrm{cm}^{3}\right) \\
3,05\end{array}$}} & \multicolumn{2}{|c|}{ Finura (\%) } & \multirow{3}{*}{\multicolumn{2}{|c|}{$\begin{array}{c}\text { Blaine } \\
\left(\mathrm{cm}^{2} / \mathrm{g}\right) \\
4538,18 \\
\end{array}$}} & \multirow{3}{*}{\multicolumn{2}{|c|}{$\begin{array}{c}\text { Água de } \\
\text { Consist. (\%) } \\
30,04\end{array}$}} & \multicolumn{2}{|c|}{ Tempo Pega $(\min$} \\
\hline & & \#200 & \#325 & & & & & & Fim \\
\hline & & 0,00 & 0,36 & & & & & 221,36 & 287,05 \\
\hline \multirow{2}{*}{\multicolumn{4}{|c|}{ Expansibilidade a }} & \multicolumn{6}{|c|}{ Resistência à Compressão (MPa) } \\
\hline & & & & 1 dia & & dias & & & \multirow{2}{*}{$\begin{array}{c}28 \text { dias } \\
48,06\end{array}$} \\
\hline \multicolumn{4}{|c|}{0,32} & 25,28 & \multicolumn{2}{|c|}{36,53} & & & \\
\hline
\end{tabular}

O hidróxido de cálcio PA foi produzido pelo fabricante Dinâmica Química Contemporânea Ltda. e o sulfato de sódio PA pelo Biotec. Os materiais foram misturados segundo recomendações da NBR 7215 [16], porém os materiais secos foram misturados e homogeneizados antes de serem colocados na argamassadeira para garantir que a adição, que é um pó muito fino, estivesse bem misturada aos materiais e evitar a formação de grumos.

Para uma avaliação mais completa da expansão das barras de argamassa, elas foram mantidas em imersão e as leituras continuaram além dos 42 dias estipulados pela NBR 13583 [14], mantendo-as imersas até os 100 dias. Findado este novo tempo estipulado de imersão, prepararam-se amostras do traço de referência e do traço contendo $20 \%$ de adição mineral, com dimensão aproximada de $5 \mathrm{~mm}$, para análise em microscópio eletrônico de varredura com EDS e para análises de distribuição de poros em porosímetro por intrusão de mercúrio.

\section{Resultados e Discussões}

A expansão resultante das barras da argamassa de referência e das argamassas com diferentes porcentagens de substituição expostas à solução de sulfato de sódio está apresentada na Figura 2. Os resultados demonstram que quanto maior a substituição, maior a expansão resultante, além de todos percentuais levarem a um aumento na expansão em relação a referência, evidenciando que a adição por pó de concreto não possui potencial em mitigar o ataque por íons sulfatos de origem externa. 


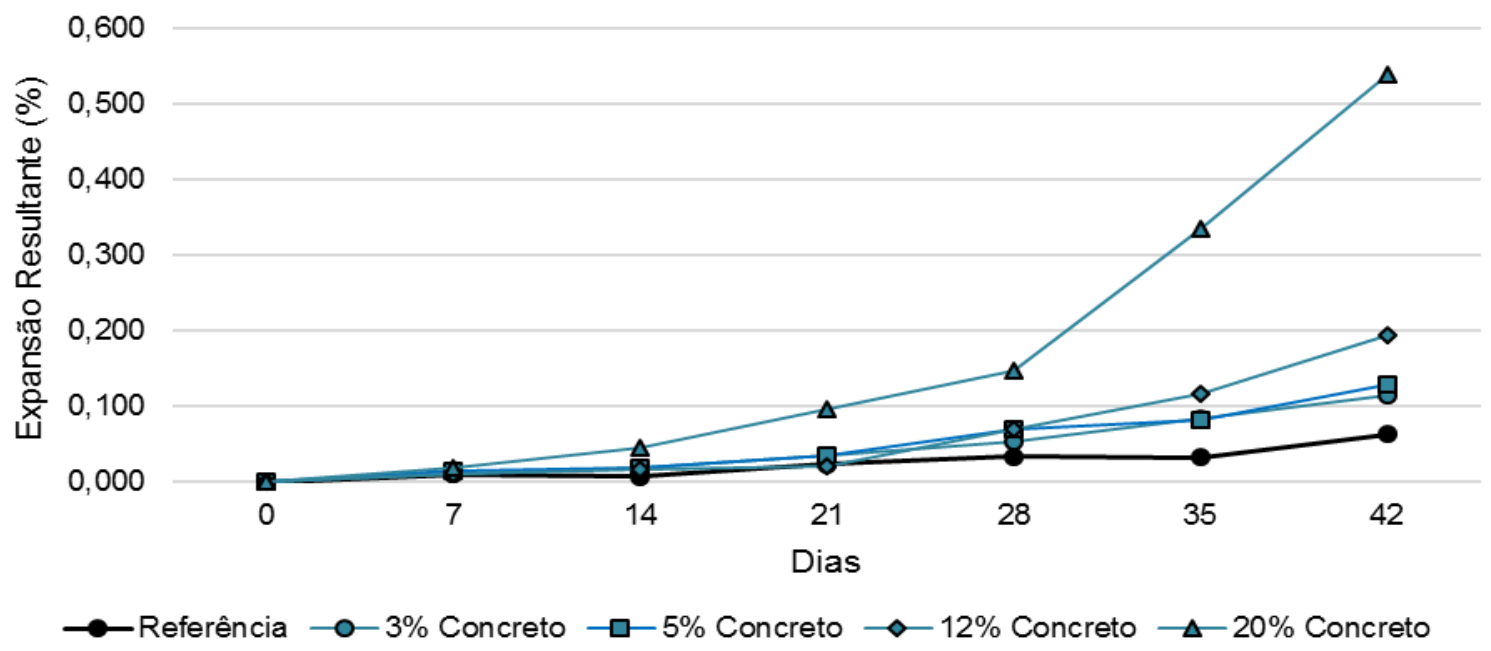

Figura 2: Expansão das argamassas contendo diferentes porcentagens da adição mineral na composição do material ligante, nas idades de $0,7,14,28,35$ e 42 dias, conforme método de ensaio NBR 13583 [14]

Os valores de expansão encontrados aos 42 dias foram comparados com o limite proposto por Marciano, 1993 [apud 8], segundo o qual nesta idade a expansão resultante limite é de $0,030 \%$ e para valores abaixo deste limite a argamassa pode ser considerada resistente ao ataque por sulfatos. Como mostrado na Figura 3, a argamassa de referência não é resistente ao ataque por sulfatos, apresentando valor de expansão superior a $0,030 \%$, e com nenhuma das porcentagens de substituição foi possível atingir o limite proposto, pelo contrário, aumentaram o valor da expansão resultante, ficando ainda mais distante de $0,030 \%$.

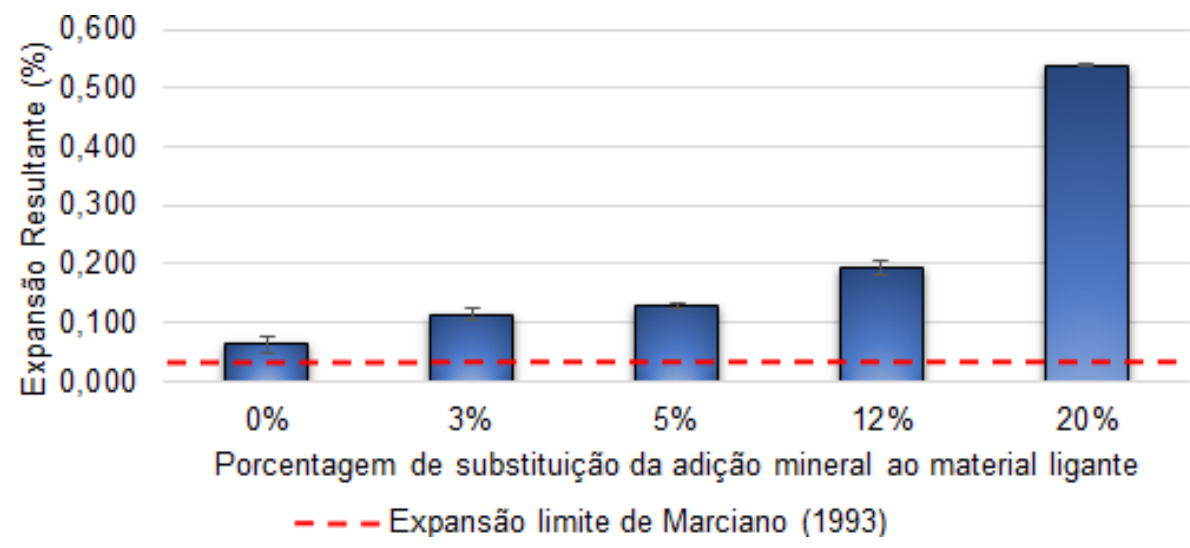

Figura 3: Expansão resultante, aos 42 dias, das argamassas contendo diferentes porcentagens da adição mineral na composição do material ligante e limite de expansão resultante proposto por Marciano, 1993 [apud 8]

Com a expansão no tempo de imersão, estendido até os 100 dias, foi possível observar todas as barras imersas na solução de sulfato de sódio apresentarem fissuras e a forma destas fissuras. As fissuras iniciaram aos 35 (argamassa com 20\%), 56 (12 e 5\%), 84 (3\%) e 98 dias (referência), apresentando-se na forma de microfissuras nestas idades para o traço de referência e de $3 \%$. Notou-se que, quanto maior a porcentagem de substituição, além da diferença de idade, as fissuras se apresentaram com maiores aberturas e comprimentos, além da maior 
tendência em conectarem-se, indicando que as argamassas ficaram mais frágeis, como pode se observar na Figura 4.

a

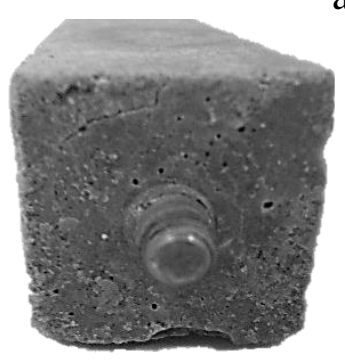

$\mathrm{b}$

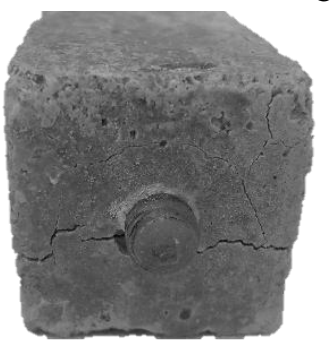

b

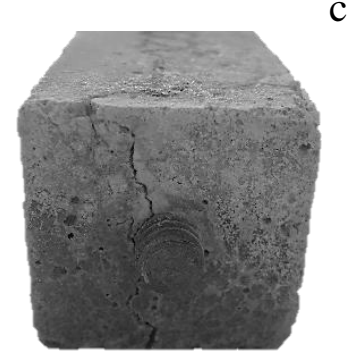

$\mathrm{c}$

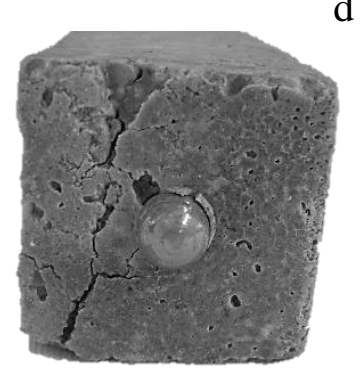

Figura 4: Fissuras das barras de argamassa com adição de pó de concreto após 100 dias de imersão em solução de sulfato de sódio: (a) 3\% de adição;

(b) $5 \%$ de adição; (c) $12 \%$ de adição; (d) $20 \%$ de adição

As imagens obtidas das microestruturas das argamassas estão de acordo com 0 apresentado pela literatura tanto na morfologia dos cristais identificados [2,17], quanto no comportamento frente ao ataque por íons sulfato [4,18]. A Figura 5 apresenta a microestrutura da argamassa de referência e da argamassa contendo $20 \%$ de pó de concreto, após 100 dias de imersão em solução saturada de cal. Pela análise foi possível identificar compostos formados na hidratação do cimento, como cristais aciculares de etringita, formações amorfas de C-S-H e placas hexagonais de portlandita.

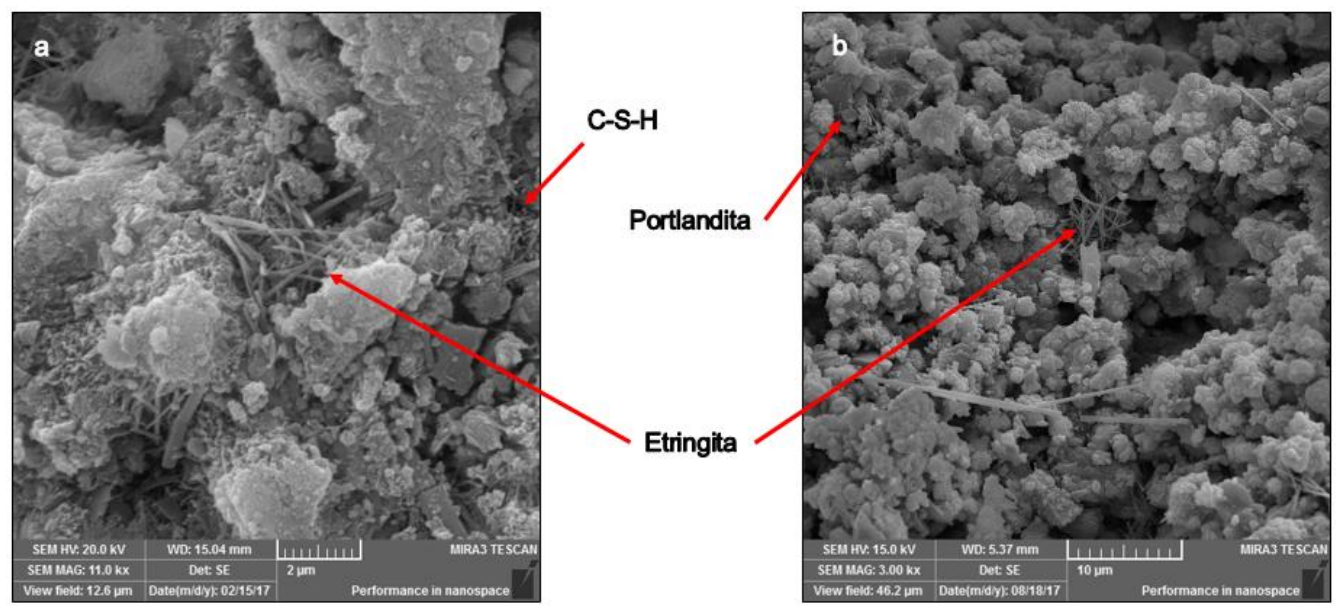

Figura 5: Imagens das fases hidratadas presentes na microestrutura das argamassas após 100 dias de imersão em solução saturada de cal:

(a) Referência; (b) $20 \%$ de adição de pó de concreto

$\mathrm{Na}$ argamassa contendo $20 \%$ de pó de concreto foi ainda possível observar pontos aglomerados na pasta pela presença da adição de resíduo de concreto, por se tratar de uma adição inerte, que não reagiu com os componentes do cimento (Figura 6).

Já nas argamassas de referência e com $20 \%$ de adição de resíduo de concreto que ficaram imersas em solução de sulfato de sódio, pode-se identificar a presença de uma grande quantidade de cristais aciculares de etringita nos poros (Figura 7), originados pela reação entre os íons sulfato da solução e os compostos da hidratação do cimento, e ainda, a ocorrência de microfissuras devido ao tensionamento gerado por estes compostos, o que está de acordo com a microestrutura de uma peça que sofreu o ataque por sulfatos $[4,18]$. Nota-se ainda 
que os cristais neste caso, além de se encontrarem em maior quantidade, apresentam-se com maiores comprimentos. Na argamassa contendo adição de resíduo de concreto os cristais de etringita originados formaram aglomerados. Acredita-se que a adição, pela disponibilidade de portlandita e calcita, agiu como ponto de nucleação para a formação da etringita.

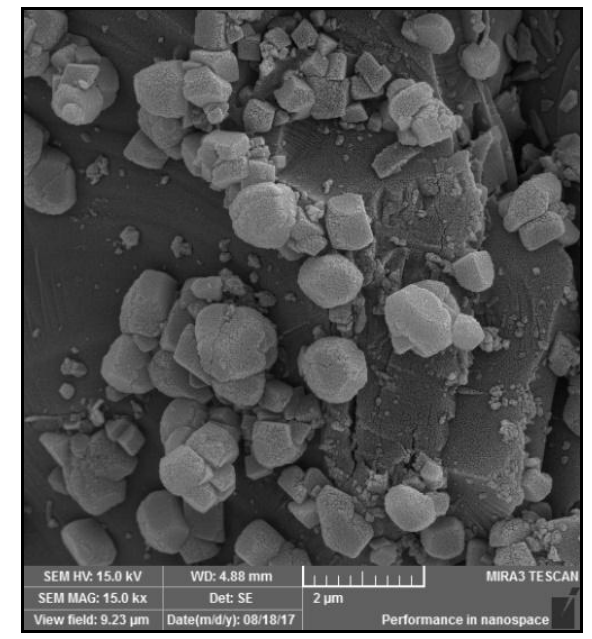

Figura 6: Imagem de micrografia da argamassa com $20 \%$ de adição de pó de concreto após 100 dias de imersão em solução de cal com presença de aglomerados da adição

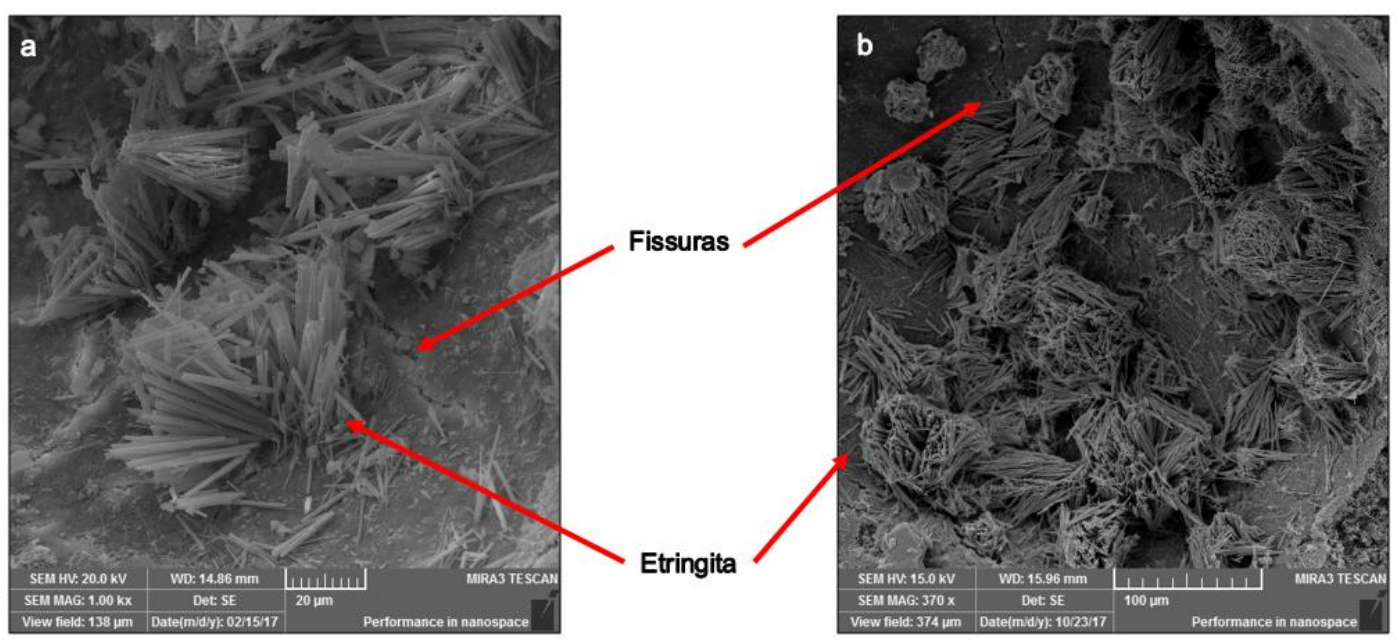

Figura 7: Imagens dos cristais e fissuras presentes na microestrutura das argamassas após 100 dias de imersão em solução de sulfato de sódio:

(a) Referência; (b) $20 \%$ de adição de pó de concreto.

O ensaio em porosimetria por intrusão de mercúrio permitiu determinar as porosidades das argamassas, apresentadas na Figura 8. Percebe uma redução de mais de $70 \%$ da porosidade nas argamassas sujeitas a solução agressiva, que corrobora com os resultados encontrados nas imagens da microestrutura, tendo em vista a grande quantidade de produtos expansivos do ataque por sulfatos formados colmatando os poros da argamassa. Nota-se ainda que a argamassa com adição de resíduo de concreto apresenta maior porosidade que a referência.

As distribuições dos tamanhos dos poros das argamassas estão apresentadas na Figura 9. Percebe-se que, com o ataque há uma redução nos poros de menor 
diâmetro, evidenciando que estes foram tamponados pelos cristais expansivos originados no ataque por sulfatos. Além disso, é possível identificar um aumento nos poros com diâmetro em torno de $30 \mu \mathrm{m}$ para a referência, e de $7 \mu \mathrm{m}$ aproximadamente para a argamassa com adição, que atribuem-se as microfissuras originadas com o avanço da manifestação patológica.

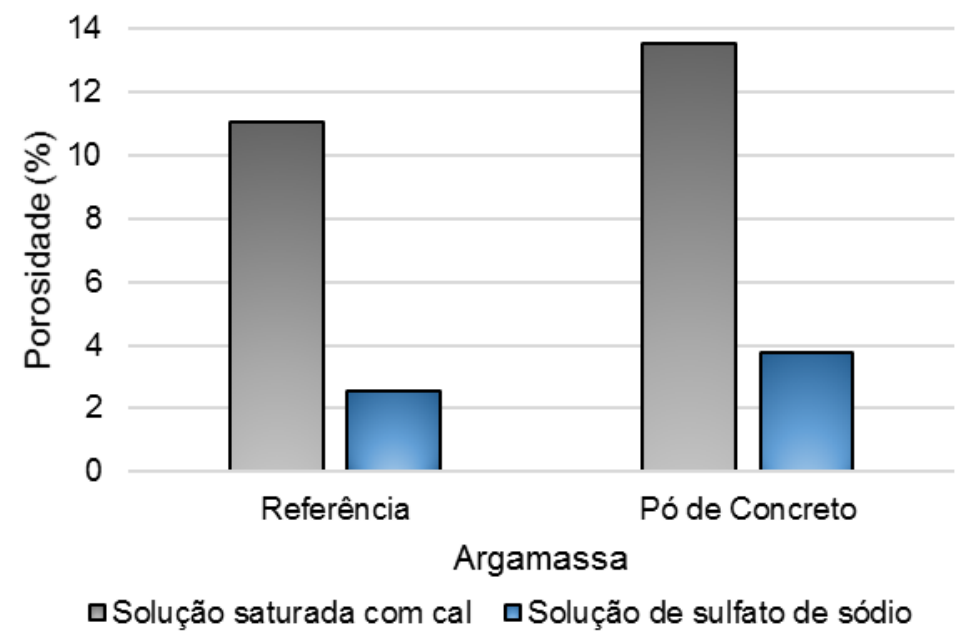

Figura 8: Porosidades das argamassas após 100 dias de imersão em soluções saturada com cal e de sulfato de sódio.

a
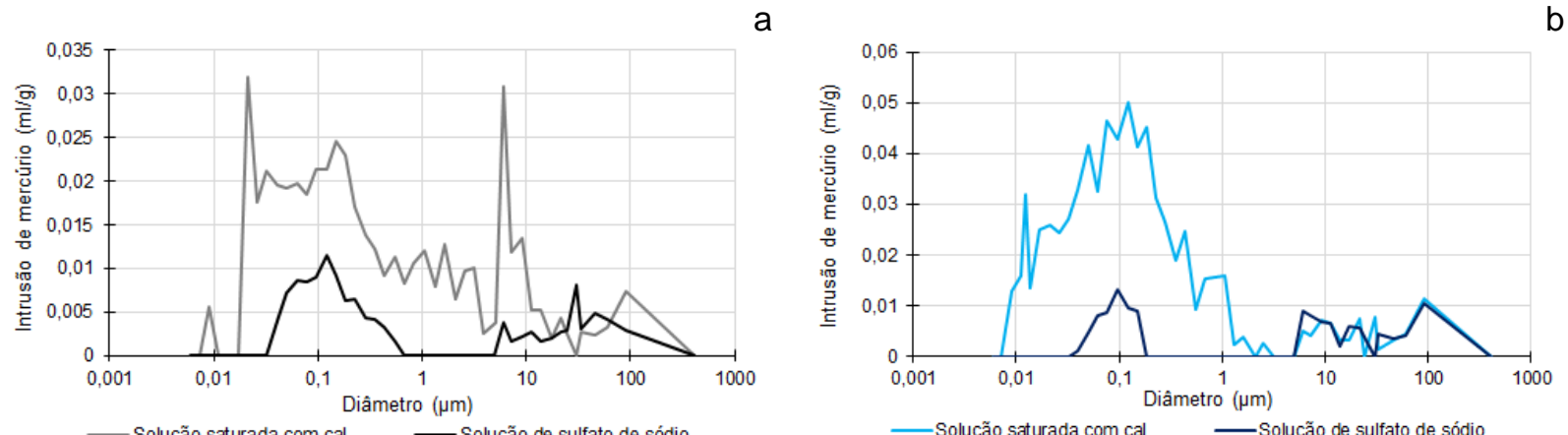

Figura 9: Distribuição dos tamanhos dos poros das argamassas após 100 dias de imersão em soluções saturada com cal e de sulfato de sódio: (a) Referência;

(b) Com $20 \%$ de adição de pó de concreto.

O resíduo de concreto não foi capaz de mitigar o ataque de sulfatos de origem externa em nenhuma das porcentagens adotadas, sendo que as argamassas com adição apresentaram expansões resultantes superiores à referência. Este fato pode ocorrer pelo aumento na porosidade da argamassa com uso da adição, que facilita a entrada dos íons agressivos na matriz, somada a uma alteração na distribuição de poros, que também influencia na capacidade de migração destes íons pela matriz. Além disso, o fato da adição possuir compostos cristalinos como a portlandita já formada, que necessita apenas decompor-se na solução dos poros para se tornar reativa, pode acelerar a sua reação com o sulfato e formação dos cristais expansivos. 


\section{Conclusões}

Neste trabalho foi avaliada a interação do pó de concreto, oriundo de RCD, em argamassas submetidos a ensaio acelerado do ataque por sulfatos de sódio de origem externa. O resíduo de concreto estudado não apresentou potencial de mitigação do ataque por sulfatos em nenhuma das porcentagens utilizadas de substituição da adição mineral na composição do material ligante.

O aumento na porcentagem de substituição levou a maior a expansão resultante nas barras de argamassa, indicando que quanto maior a quantidade de adição utilizada, maior a suscetibilidade das argamassas ao ataque por sulfatos. Além disso, quanto maior a porcentagem de substituição as argamassas apresentaram fissuras em idades menores, denotando maior fragilidade.

A argamassa com adição de resíduo de concreto apresentou maior porosidade que a de referência. As argamassas de referência e com adição de resíduo de concreto imersas em solução de sulfato de sódio apresentaram grande quantidade de cristais de etringita nos poros da microestrutura, justificando a expansão das barras. Observou-se uma redução na porosidade das argamassas sujeitas ao ataque, que se deve a formação dos cristais de etringita nos poros. Com o ataque, as argamassas mudaram também a distribuição do tamanho dos poros, indicando que os poros de menores diâmetros foram tamponados pelos cristais expansivos.

\section{Agradecimentos}

À Fundação Araucária pelo apoio financeiro através da bolsa de estudos. Ao laboratório multiusuários - CLABMU da UEPG. Ao Instituto LACTEC e a Universidade Federal do Paraná pela colaboração durante o desenvolvimento deste trabalho.

\section{Referências}

[1] HOPPE FILHO, J. Efeitos da adição de cal hidratada sobre a permeabilidade ao oxigênio e absorção capilar de concreto com altos teores de adições minerais. Dissertação (Mestrado) - Universidade Federal de Santa Maria. Santa Maria, 2002.

[2] MEHTA, P. K.; MONTEIRO, P. J. M. Concreto: estrutura, propriedades e materiais. 3ª Edição. São Paulo: IBRACON, 2008.

[3] NEVILLE, A. M. Propriedades do concreto. 5 Edição. Porto Alegre: Bookman, 2016.

[4] SKALNY, J.; MARCHAND, J.; ODLER, I. Sulfate attack on concrete. New York. Spon spress. 2002.

[5] RIBEIRO, D. V.; SALES, A.; SOUZA, C. A. C.; ALMEIDA, F. C. R.; CUNHA, M. P. T.; LOURENÇO, M. Z.; HELENE, P. Corrosão em Estruturas de Concreto Armado: Teoria, Controle e Métodos de Análise. 1ª Edição. Rio de Janeiro: Elsevier, 2014. 
[6] SOUZA, D. J. Capacidade de adições minerais em mitigar o ataque por sulfatos de sódio e magnésio em argamassas de cimento portland. Dissertação (Mestrado) - Universidade Federal do Paraná. Curitiba, 2016. [7] SILVA FILHO, L. C. F. Durabilidade do Concreto à Ação de Sulfatos: uma análise do efeito da permeação de água e da adição de microssílica. Dissertação (Mestrado) - Universidade Federal do Rio Grande do Sul. Porto Alegre, 1994.

[8] HOPPE FILHO, J.; SOUZA, D. J.; MEDEIROS, M. H. F. de; PEREIRA, E.; PORTELA, K. F. Ataque de matrizes cimentícias por sulfato de sódio: adições minerais como agentes mitigadores. Cerâmica 61, 168-177. 2015.

[9] MORAES, R. C. Efeitos físicos e pozolânicos das adições minerais sobre a resistência mecânica do concreto. Dissertação (Mestrado) - Universidade Federal de Santa Maria. Santa Maria, 2001.

[10] MEDEIROS, M. H. F.; SOUZA, D. J.; HOPPE FILHO, J.; ADORNO, C. S.; QUARCIONI, V. A.; PEREIRA, E. Resíduo de cerâmica vermelha e fíler calcário em compósito de cimento Portland: efeito no ataque por sulfatos e na reação álcali-sílica. Matéria (Rio J.) vol.21 no. 2 Rio de Janeiro Apr./June 2016.

[11] FLOREA, M.V.A.; NING, Z.; BROUWERS, H.J.H. Activation of liberated concrete fines and their application in mortars. Construction and Building Materials 50 (2014) 1-12.

[12] BARTHEL, M.; RÜBNER, K.; KÜHNE, H.C; ROGGE, A.; DEHN, F. From waste materials to products for use in the cement industry. Advances in Cement Research, 2016, 28(7), 458-468.

[13] OKSRI-NELFIA, L.; P-Y. MAHIEUX, P. Y.; AMIRI, O.; TURCRY, P.; LUX, J. Reuse of recycled crushed concrete fines as mineral addition in cementitious materials. Materials and Structures, 2016, Vol.49(8), pp.3239-3251.

[14] ASSOCIAÇÃO BRASILEIRA DE NORMAS TÉCNICAS. NBR 13583: Cimento Portland - Determinação da variação dimensional de barras de argamassa de cimento Portland expostas à solução de sulfato de sódio. Rio de Janeiro, 2014.

2009.

NBR 7214: Areia Normal para ensaio de Cimento. Rio de Janeiro, compressão, 1996.

[17] QUARCIONI, V. A. Influência da cal hidratada nas idades iniciais da hidratação do cimento Portland - Estudo em pasta. Tese (Doutorado) Universidade de São Paulo. São Paulo, 2008.

[18] SANTHANAM, M.; COHEN, M. D.; OLEK J. Mechanism of sulfate attack: A fresh look. Part 1: Summary of experimental results. Cement and Concrete Research, nำ, p.915-921, 2002. 